\title{
CBCT AND SEM EVALUATION OF MARGINAL AND INTERNAL FIT OF LITHIUM DISILICATE COPINGS FABRICATED WITH 2 DIFFERENT TECHNIQUES (IN VITRO STUDY)
}

\author{
Iman El Aily* and Sahar H El Dessouky**
}

\begin{abstract}
Statement of the problem. The marginal \& internal adaptation of all-ceramic crowns may vary depending on the technique of fabrication and the methodology of measurement.

Purpose. To evaluate the marginal and internal adaptation of lithium disilicate crown copings fabricated with two techniques using two measuring modalities, cone beam computed tomography CBCT and scanning electron microscopy (SEM).

Materials and methods. The materials selected were Emax CAD for CEREC inlab (Group 1) and Emax Press for the lost wax and heat pressing (Group2). 10 copings were designated for each group. The copings were cemented on standardized epoxy resin dies with self-adhesive resin cement RelyX Uncem. A CBCT system was used to obtain measurements from reconstructed slices in two orthogonal planes for each sample, and a scanning electron microscope (SEM) was used for cross-sectioned samples. Mean, SD, median, range and 95\% confidence level were calculated using Kolmogrov-Smirnov test and comparison of the ceramic types and methodology of testing were accomplished with Mann-Whitney U test and Spearman correlation tests respectively the significance level being set at $\mathrm{P}<0.05$.
\end{abstract}

Results. Heat pressing exhibited lower vertical gap margin in SEM 22.7um $( \pm 5.3)$ than Emax CAD 47um ( \pm 16.1$)$. The overall values of misfit of Emax CAD were significantly higher than Emax press in SEM \& CBCT measurements. There was statistical correlation between the two measuring methods in both the mesial, lingual and total measurements according to Spearman correlation test.

Conclusion. The Emax press has a better overall marginal and internal fit than the Emax CAD, still the values are clinically acceptable for both.

* Lecturer Department of Fixed Prothodontics, Cairo University

** Associate Professor Department of Oral Radiology, Cairo University 


\section{INTRODUCTION}

All ceramic restorations exhibit appealing properties such as enamel-like translucency, biocompatibility, color stability and esthetics ${ }^{(1-3)}$. The increasing demand on these restorations prompted the evolution of modern ceramic materials with improved microstructure together with new fabrication techniques ${ }^{(2,4)}$. One of these materials is the lithium disilicate that can be fabricated in laboratory by the lost wax technique where Ingots are heat pressed into a refractory mold created by the lost wax. The heat pressing procedure avoids the heterogeneity of sintering in the conventional method, as the lithium disilicate crystals embedded in the glassy matrix avoid crack propagation and improve mechanical stability ${ }^{(5,6)}$. The CAD/CAM is another technique. It reduces the chair side interval and the restoration is fabricated through intra-oral optical impression and in-office milling in a single visit whereby prefabricated blocks are milled then heat crystallized in a porcelain furnace ${ }^{(2,7)}$.

Marginal fit is important in the success of the restorations. Failure to provide such a fit leads to many sequelae such as plaque accumulation, gingival inflammation, dissolution of the luting agent, secondary caries, periodontal breakdown and consequently failure of the restoration ${ }^{(8-11)}$. The marginal fit is affected by, preparation design (11-13), margin configuration, die spacer settings, and thickness of the luting cement ${ }^{(14)}$.

The marginal fit of prosthetic restorations has been assessed in many studies and with various methods, including the use of an explorer or visual examination $^{(15)}$ and starting from the conventional radiographic techniques ${ }^{(8,16,17)}$ passing through the more sophisticated SEM ${ }^{(13,18,19)}$, dye penetration testing ${ }^{(20,21)}$, stereomicroscopy ${ }^{(12)}$, optical microscopic scanning ${ }^{(14,22)}$ laser videography ${ }^{(4)}$ and micro-computed tomography ${ }^{(9,10,23-27)}$.

The internal fit has been measured in one or two dimensional contexts through optical, replica, weight or SEM. The sample size ranged from 5-10 in number and the measuring points ranged from 2-150 selected in a systematic or random manner. The studies led to varying results and conclusions ${ }^{(28)}$. Enlarged internal incongruities might lead to incomplete seating and incomplete bonding of the interfaces compromising the fracture resistance and mechanical stability of the restoration ${ }^{(5)}$. The marginal gap distance measurements ranged from 30-120um and margins less 75- 120 microns were considered clinically acceptable ${ }^{(29)}$.

Cone beam computed tomography (CBCT) is a radiographic modality which has been adapted for clinical use in 1982 and, in 2001, the first system used for dento-maxillofacial imaging became commercially available in the market as an alternative to conventional $\mathrm{CT}^{(30)}$. In CBCT systems, the $\mathrm{x}$-ray beam is pyramidal or cone-shaped and only one rotation is required to perform the scan which allows for a very short scan time thus reducing the possibility of motion artifacts ${ }^{(31,32)}$. The primary beam is collimated, thus limiting the radiation to the area of interest with consequent dramatic reduction of the dose delivered to the patient compared to multislice $\mathrm{CT}^{(33,34)}$.

$\mathrm{CBCT}$ produces isotropic volumetric images with a voxel size as small as $0.1 \mathrm{~mm}$ which contributes to the accuracy of the images and achieves a level of spatial resolution that is accurate enough for precise measurements ${ }^{(35)}$. Additionally, there is absence of image magnification and the yielded images have a very low level of metal artifacts thus providing more reliable information $(31,33,36)$. Moreover, secondary reconstruction of the CBCT data is performed by a personal computer which presents a unique advantage over medical $\mathrm{CT}$ in which access and interaction is only possible through workstations ${ }^{(37)}$.

Last but not least, the CBCT equipment has a substantially reduced size and cost compared to medical CT, which makes it more suited for the dental office ${ }^{(33,38,39)}$. 
Consequently, CBCT has the potential to become a routine non-invasive diagnostic instrument for various dental applications. It complements the diagnosis in indications that require more elaborate information and it also reduces the need for CT scans for dental issues ${ }^{(40)}$. It allows an enhanced level of diagnosis and, ultimately, treatment decision making $^{(41)}$.

Unfortunately, to the best of our knowledge, evaluation of the restorations marginal and internal misfit using CBCT has received very little attention.

The purpose of this study is to evaluate the effect of heat pressing and chair side CAD/ CAM technique of lithium disilicate crowns on the marginal and internal fit using CBCT and SEM in vitro and to test the possibility of using CBCT for this application as compared to SEM.

\section{MATERIALS AND METHODS}

An upper left premolar typodent was prepared with Vita IN ceram diamond stone kit (Vita Inceram No's, H016 tapered with flat end, H018 pearshaped -Shleifkoperset Germany) form a single die. The die comprised 9mm BL cervical diameter, $7.5 \mathrm{~mm}$ MD diameter and $4 \mathrm{~mm}$ OG height with $1 \mathrm{~mm}$ finish line conforming to the cervical contour and a 6 degree overall taper. The occlusal surface was made in 2 planes with a functional bevel of the palatal cusp (Figure 1).

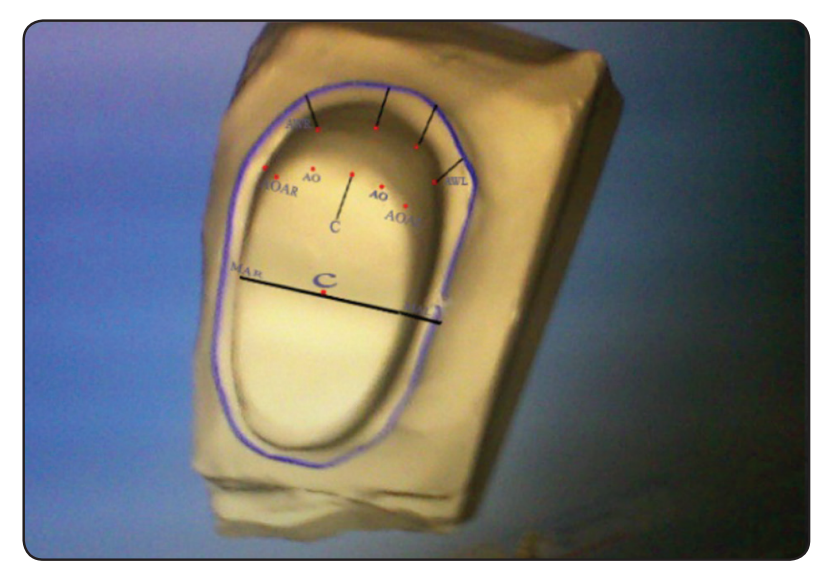

Fig. (1) Virtual image of the prepared tooth from the CEREC in lab

\section{Impression making}

The prepared tooth was duplicated 20 times with a single step dual viscosity PVS addition silicon impression material (Imprint II putty and light 3M ESPE Seefeld, Germany) the impressions were loaded in customized trays made for the typodont model arch as employed by Schaefer $\mathrm{O}$ et al. (5) which can be summarized as follows: the model arch was fastened to a rectangular base containing 3 conical guiding pins to ensure standardized tray positioning. The light body was injected on and around the prepared tooth and dispersed lightly with an air syringe for 3 seconds. A customized sectional tray filled with putty was seated in position without applying any force. After setting, polymerization was left for a prolonged interval 3 times more than recommended by the manufacturer. Impressions were removed with a snap and were poured epoxy resin dies (Poltpoxy700 Polymer, CIC, Cairo Egypt) for the fabrication of the two ceramic types.

\section{Coping fabrication}

For the CAD/CAM, the CEREC 3D Extraoral optical scanner (InEos Sirona Dental Systems $\mathrm{GmbH}$ ) was used for making the optical impression. The copings were designed in the CEREC in lab 3D software (v4.2) with die spacer and luting space set to $35 \mu \mathrm{m} \& 20 \mu \mathrm{m}$ respectively. A CEREC inlab MXCL unit was used for CAM processing of the copings.

For the HP group (IPS emax press), the copings were waxed in a counter die made of the exact dimensions of the CEREC copings. The copings were then invested and the wax eliminated. Glass ceramic ingots of IPS Emax Press were plasticized at 930Cand pressed into each investment mold (Press vest speed Ivoclar Vivadent AG), with 500kPa pressure (EP500 press furnace; Ivoclar Vivadent AG). 


\section{CBCT measurements}

CBCT images were acquired using a Next Generation i-CAT Scanner (Imaging Sciences International, Inc., Hatfield, USA).

Each cast with the restoration in place was seated on a plate mounted on the machine, specially designed for imaging of the specimens. The casts were placed with the mid-sagittal plane perpendicular to the horizontal plane and they were aligned in the scanner according to the vertical and horizontal laser adjustment light beams. Then a scout view (preview) was obtained in order to perform any required adjustments before image acquisition.

The machine is supplied with an Amorphous Silicon Flat Panel Sensor with Cesium Iodide (CsI) scintillator. It has a $0.5 \mathrm{~mm}$ focal spot, 14 Bit gray scale resolution, and it was operated at the following protocol for all the scans of the study:

$\begin{array}{cl}\text { Tube voltage } & 120 \mathrm{kVp} \\ \text { Milliampere } & 37.07 \mathrm{mAs} \\ \text { Voxel size } & 0.125 \mathrm{~mm} \\ \text { Scanning time } & 26.9 \text { seconds } \\ \text { Field of view } & 4 \mathrm{~cm} \text { Height } * 16 \mathrm{~cm} \text { Diameter }\end{array}$

After acquisition, the data were exported and transferred in DICOM format and downloaded via a Compact Disk (CD) to a personal computer for linear measurements, where, Invivo Dental software (version 5.3; Anatomage, San Jose, CA, USA) was utilized.

\section{Measuring the internal gaps:}

At the software interface, Section module was the one of choice to obtain all the measurements, where all the data were presented in axial, coronal and sagittal perspectives.

Two observers with different experience periods were involved in the study and they were asked to follow the same protocol to take the measurements.
For each restoration, the reference lines were set using the reorientation tool at the three views to intersect at the center of the restoration and to be parallel to the long axis of the die and restoration as well. All dies were presented in the bucco-lingual and mesio-distal directions in sagittal and coronal perspectives of the software according to their alignment during scan acquisition. The reference bucco-lingual section was taken passing through the buccal and palatal cusp tips of the crown restoration. Additional cross-sections were obtained on either sides of this reference line at $0.5 \mathrm{~mm}$ intervals for a total of five bucco-lingual sections. The reference mesio-distal section was taken passing through the central groove of the crown restoration. Additional cross-sections were obtained on either sides of this reference line at $0.5 \mathrm{~mm}$ intervals for a total of five mesio-distal sections. The points of internal fit measurements were standardized in the buccolingual and mesio-distal orientation.

Seven measuring locations were used in each section (Figure 2):

1. Gap at the finishing line (one on each side of the preparation): it is the global distance between the tip of the crown margin and the outermost point at the finishing line of the die.

2. Axial wall gap (one on each side of the preparation): measured as the horizontal distance from the internal surface of the crown to the axial wall of the die, at the widest detectable diameter of the gap.

3. Occluso-axial gap (one on each side of the preparation): measured from the internal surface of the crown at the junction between the occlusal and axial walls to the corresponding point on the prepared surface of the die.

4. Center of occlusal surface: perpendicular measurement from the most apical point of the internal surface of the crown on the occlusal wall to the corresponding point on the occlusal surface of the prepared die at the widest detectable diameter of the gap. 


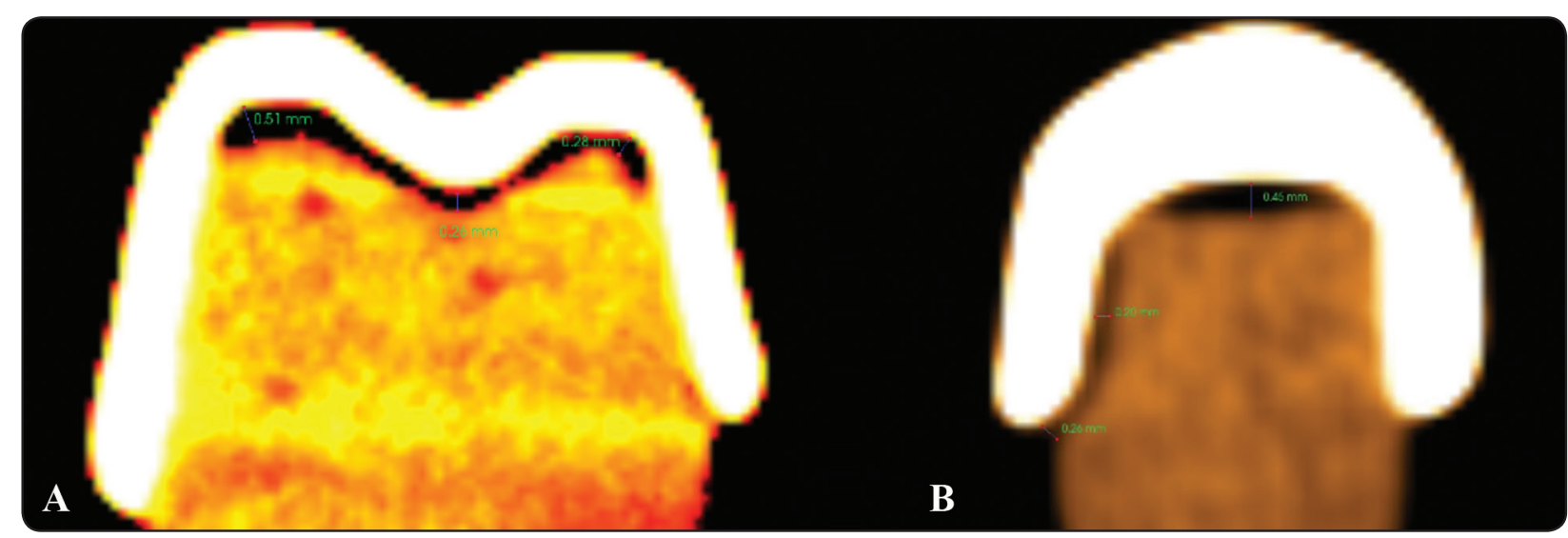

Fig. (2): CBCT measurements of the internal fit on a bucco-ligual (A) and mesio-distal sections (B).

\section{SEM sample preparation}

The fitting surface of the crowns were air abraded with air borne particle of $100 \mu \mathrm{m}$ alumina, treated with ethanol alcohol in an ultrasonic device, fixed to the master dies by RelyX Unicem (3M ESPE AG, Germany) and subjected to a $3 \mathrm{Kg}$ constant pressure in a special mounting device to ensure complete seating, for the vertical marginal gap measurement. Upon completion of the experiment, in order to measure the internal fit, all samples were embedded in acrylic resin (Acrostone Wliw England). 5 samples were cut in halves MD and the measuring points were mid: lingual, buccal, mesial, and distal and another 4 points in between. A set of 5 other samples were sectioned BL and the same measuring points of the MD section were determined (Figure 3). Sectioning was done with an Isomet low speed micro saw (Buehler USA) under copious cooling.

The samples were then sputtered with gold for $4 \mathrm{~min}$ in a standard sputtering machine (S150 A Edwards, Sussex UK) under vacuum. Marginal and internal gap measurements were performed on JSMT-330 Scanning microscope) using JXA electron probe micro analyzer (JEOL) with magnification factor of $80 \& 100$. The gap between the crown coping and the demarcated points of the preparation was determined.

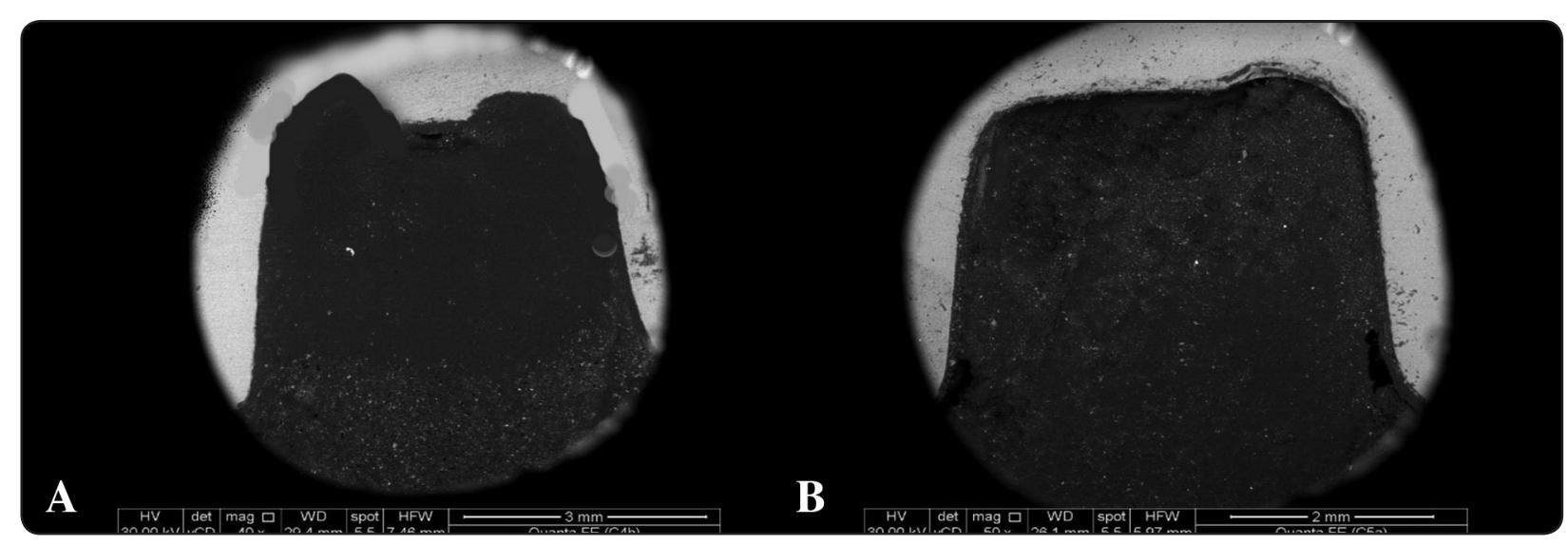

Fig. (3): SEM (A) BL section and (B) MD section

\footnotetext{
${ }^{\circledR}$ IBM Corporation, NY, USA.

${ }^{\circledR}$ SPSS, Inc., an IBM Company.
} 


\section{Statistical analysis}

Numerical data were explored for normality by checking the data distribution, calculating the mean and median values and using KolmogorovSmirnov and Shapiro-Wilk tests. All data showed non parametric distribution. Data were represented as mean, standard deviation (SD), median, range and $95 \%$ Confidence interval $(95 \% \mathrm{CI})$ values. Mann-Whitney U test was used to compare between the two ceramic types. Spearman correlation test was used to test the two measuring methods. The significance level was set at $\mathrm{P} \leq 0.05$. Statistical analysis was performed with IBM ${ }^{\circledR}$ SPSS $^{\circledR}$ Statistics Version 20 for Windows.

\section{RESULTS}

\section{Comparison between the vertical gaps of the two ceramic types by SEM}

At the buccal surface, Emax CAD showed statistically significantly lower mean gap distance than Heat pressed Emax.
While at the lingual, mesial as well as distal surfaces, Emax CAD showed statistically significantly higher mean gap distance than Heat pressed Emax. As regards the mean of the four surfaces, Emax CAD showed statistically significantly higher mean gap distance than Heat pressed Emax.

TABLE (2) Mean, standard deviation (SD) values and results of comparison between vertical gap distance values of the two ceramic types by SEM

\begin{tabular}{|c|c|c|c|c|c|}
\hline & \multicolumn{2}{|c|}{ Emax CAD } & \multicolumn{2}{c|}{$\begin{array}{c}\text { Heat pressed } \\
\text { Emax }\end{array}$} & \multirow{2}{*}{ P-value } \\
\cline { 2 - 6 } Surface & Mean & SD & Mean & SD & \\
\hline Buccal & 17.2 & 8.2 & 21.3 & 5.2 & $0.005^{*}$ \\
\hline Lingual & 43.8 & 26.9 & 27.1 & 7.8 & $<0.001^{*}$ \\
\hline Mesial & 32.8 & 11.4 & 23.8 & 8.0 & $<0.007^{*}$ \\
\hline Distal & 95.8 & 55.1 & 18.8 & 4.4 & $<.001^{*}$ \\
\hline
\end{tabular}

TABLE (1) Descriptive statistics of the vertical marginal gap distance $(\mu \mathrm{m})$ values by SEM

\begin{tabular}{|c|c|c|c|c|c|c|c|c|}
\hline \multirow[b]{2}{*}{ Ceramic } & \multirow[b]{2}{*}{ Surface } & \multirow[b]{2}{*}{ Mean } & \multirow[b]{2}{*}{ SD } & \multirow[b]{2}{*}{ Median } & \multirow[b]{2}{*}{ Minimum } & \multirow[b]{2}{*}{ Maximum } & \multicolumn{2}{|c|}{$95 \% \mathrm{CI}$} \\
\hline & & & & & & & $\begin{array}{l}\text { Lower } \\
\text { bound }\end{array}$ & $\begin{array}{l}\text { Upper } \\
\text { bound }\end{array}$ \\
\hline \multirow{5}{*}{ Emax CAD } & Buccal & 17.2 & 8.2 & 20.4 & 2.9 & 26.4 & 13.0 & 21.4 \\
\hline & Lingual & 43.8 & 26.9 & 32.1 & 20.4 & 113.7 & 30.0 & 57.7 \\
\hline & Mesial & 32.8 & 11.4 & 32.1 & 14.9 & 55.4 & 26.9 & 38.6 \\
\hline & Distal & 95.8 & 55.1 & 107.8 & 14.6 & 172.0 & 67.4 & 124.1 \\
\hline & Mean of all surfaces & 47.4 & 16.1 & 46.9 & 17.6 & 86.7 & 35.6 & 59.3 \\
\hline \multirow{5}{*}{$\begin{array}{c}\text { Heat pressed } \\
\text { Emax }\end{array}$} & Buccal & 21.3 & 5.2 & 20.6 & 14.6 & 26.4 & 16.5 & 26.1 \\
\hline & Lingual & 27.1 & 7.8 & 26.2 & 20.4 & 43.7 & 19.9 & 34.4 \\
\hline & Mesial & 23.8 & 8.0 & 20.4 & 14.9 & 32.1 & 16.4 & 31.2 \\
\hline & Distal & 18.8 & 4.4 & 20.4 & 14.6 & 26.2 & 14.7 & 22.8 \\
\hline & Mean of all surfaces & 22.8 & 5.3 & 20.5 & 17.6 & 32.1 & 17.9 & 27.7 \\
\hline
\end{tabular}


Comparison between the internal fit of the two ceramic types by SEM

At the Center point; Emax CAD showed statistically significantly higher mean gap than heat pressed Emax at the distal and lingual surfaces. At the mesial surface, there was no statistically significant difference between the two ceramic types. At the buccal surface, heat pressed Emax showed statistically significantly higher mean gap than Emax CAD.

At the Occluso-Axial angle; Emax CAD showed statistically significantly higher mean gap than heat pressed Emax at all surfaces.

At the Axial point; Emax CAD showed statistically significantly higher mean gap than heat pressed Emax at the mesial, distal and lingual surfaces. At the buccal surface, there was no statistically significant difference between the two ceramic types.

At the Shoulder Area; Emax CAD showed statistically significantly higher mean gap than heat pressed Emax at the mesial, distal and lingual surfaces. At the buccal surface, there was no statistically significant difference between the two ceramic types.

As regards the overall mean gap at all surfaces; Emax CAD showed statistically significantly higher mean gap than heat pressed Emax at all surfaces.

TABLE (3) Mean, standard deviation (SD) values and results of comparison between the internal fit of the two ceramic types by SEM

\begin{tabular}{|c|c|c|c|c|c|c|}
\hline \multirow{2}{*}{$\begin{array}{c}\text { Point of } \\
\text { measurement }\end{array}$} & \multirow{2}{*}{ Surface } & \multicolumn{2}{|c|}{ Emax CAD } & \multicolumn{2}{|c|}{ Heat pressed Emax } & \multirow{2}{*}{$P$-value } \\
\hline & & Mean & SD & Mean & SD & \\
\hline \multirow{5}{*}{ Center } & M & 49.79 & 47.35 & 48.47 & 104.03 & 0.091 \\
\hline & $\mathrm{D}$ & 45.44 & 18.25 & 15.60 & 17.24 & $0.043 *$ \\
\hline & $\mathrm{B}$ & 16.99 & 18.29 & 37.63 & 17.64 & $0.027 *$ \\
\hline & $\mathrm{L}$ & 54.68 & 88.14 & 26.83 & 6.34 & $0.003 *$ \\
\hline & M & 165.72 & 59.86 & 69.73 & 74.04 & $<0.001 *$ \\
\hline \multirow{3}{*}{$\begin{array}{l}\text { Occluso-Axial } \\
\text { Angle }\end{array}$} & $\mathrm{D}$ & 95.00 & 42.88 & 45.07 & 28.78 & $<0.001 *$ \\
\hline & $\mathrm{B}$ & 180.74 & 151.34 & 24.57 & 5.20 & $<0.001^{*}$ \\
\hline & $\mathrm{L}$ & 191.53 & 149.78 & 24.64 & 6.78 & $<0.001 *$ \\
\hline \multirow{4}{*}{ Axial } & M & 52.45 & 11.52 & 26.71 & 14.94 & $<0.001 *$ \\
\hline & $\mathrm{D}$ & 49.65 & 16.00 & 17.29 & 14.46 & $<0.001 *$ \\
\hline & B & 30.07 & 15.05 & 59.65 & 26.11 & $<0.001 *$ \\
\hline & $\mathrm{L}$ & 123.08 & 146.54 & 32.29 & 13.90 & $<0.001 *$ \\
\hline \multirow{4}{*}{ Shoulder Area } & M & 137.68 & 32.47 & 32.90 & 25.70 & $<0.001 *$ \\
\hline & $\mathrm{D}$ & 139.02 & 23.08 & 28.08 & 12.85 & $<0.001^{*}$ \\
\hline & B & 42.80 & 9.98 & 37.65 & 22.05 & 0.066 \\
\hline & $\mathrm{L}$ & 39.60 & 13.26 & 18.80 & 3.97 & $<0.001 *$ \\
\hline \multirow{4}{*}{ Total } & M & 82.84 & 66.28 & 44.61 & 69.88 & $<0.001 *$ \\
\hline & $\mathrm{D}$ & 85.63 & 46.80 & 24.21 & 20.71 & $<0.001 *$ \\
\hline & B & 69.30 & 102.88 & 38.78 & 21.27 & $<0.001 *$ \\
\hline & $\mathrm{L}$ & 98.79 & 121.88 & 25.53 & 8.92 & $<0.001 *$ \\
\hline
\end{tabular}

*: Significant at $P \leq 0.05$ 


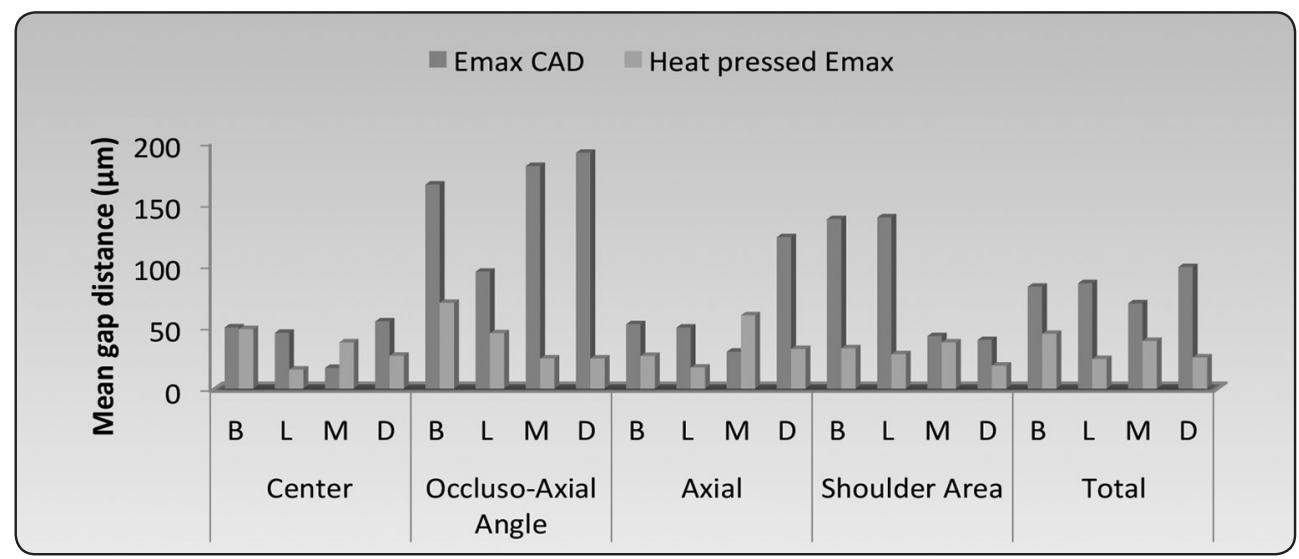

Fig. (4): Bar chart representing the comparison of the internal fit of the two ceramic types by SEM

Comparison between the internal fit of the two ceramic types by $\mathrm{CBCT}$

At the Center point; Emax CAD showed statistically significantly higher mean gap than heat pressed Emax at the distal, buccal and lingual surfaces. At the mesial surface, there was no statistically significant difference between the two ceramic types.

At the Occluso-Axial angle; Emax CAD showed statistically significantly higher mean gap than heat pressed Emax at all surfaces.

At the Axial point; Emax CAD showed statistically significantly higher mean gap than heat pressed Emax at all surfaces.

At the Shoulder Area; Emax CAD showed statistically significantly higher mean gap than heat pressed Emax at all surfaces except the buccal surface, where there was no statistically significant difference between the two ceramic types.

As regards the overall mean gap at all surfaces; Emax CAD showed statistically significantly higher mean gap than heat pressed Emax at all surfaces.
TABLE (4): Mean, standard deviation (SD) values and results of comparison between the internal fit of the two ceramic types by CBCT

\begin{tabular}{|c|c|c|c|c|c|c|}
\hline \multirow{2}{*}{$\begin{array}{c}\text { Point of } \\
\text { measurement }\end{array}$} & \multirow{2}{*}{ 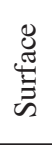 } & \multicolumn{2}{|c|}{ Emax CAD } & \multicolumn{2}{|c|}{$\begin{array}{l}\text { Heat pressed } \\
\text { Emax }\end{array}$} & \multirow[t]{2}{*}{$P$-value } \\
\hline & & Mean & SD & Mean & SD & \\
\hline \multirow{4}{*}{ Center } & M & 0.25 & 0.19 & 0.21 & 0.13 & 0.124 \\
\hline & $\mathrm{D}$ & 0.26 & 0.12 & 0.20 & 0.14 & $0.013 *$ \\
\hline & $\mathrm{B}$ & 0.19 & 0.15 & 0.10 & 0.06 & $0.022 *$ \\
\hline & $\mathrm{L}$ & 0.22 & 0.14 & 0.15 & 0.18 & $0.049 *$ \\
\hline \multirow{4}{*}{$\begin{array}{c}\text { Occluso- } \\
\text { Axial } \\
\text { Angle }\end{array}$} & M & 0.29 & 0.22 & 0.04 & 0.08 & $<0.001 * *$ \\
\hline & $\mathrm{D}$ & 0.28 & 0.18 & 0.06 & 0.12 & $<0.001 * *$ \\
\hline & $\mathrm{B}$ & 0.21 & 0.16 & 0.04 & 0.08 & $<0.001 * *$ \\
\hline & $\mathrm{L}$ & 0.26 & 0.13 & 0.10 & 0.20 & $<0.001 * *$ \\
\hline \multirow{4}{*}{ Axial } & M & 0.18 & 0.12 & 0.04 & 0.08 & $<0.001 * *$ \\
\hline & $\mathrm{D}$ & 0.22 & 0.13 & 0.03 & 0.05 & $<0.001 * *$ \\
\hline & $\mathrm{B}$ & 0.18 & 0.16 & 0.06 & 0.08 & $<0.001 * *$ \\
\hline & $\mathrm{L}$ & 0.16 & 0.21 & 0.05 & 0.09 & $<0.001 * *$ \\
\hline \multirow{4}{*}{$\begin{array}{c}\text { Shoulder } \\
\text { Area }\end{array}$} & $\mathrm{M}$ & 0.24 & 0.12 & 0.03 & 0.06 & $<0.001 * *$ \\
\hline & $\mathrm{D}$ & 0.15 & 0.08 & 0.08 & 0.15 & $<0.001 * *$ \\
\hline & $\mathrm{B}$ & 0.11 & 0.06 & 0.09 & 0.18 & 0.082 \\
\hline & $\mathrm{L}$ & 0.25 & 0.13 & 0.03 & 0.06 & $<0.001 * *$ \\
\hline \multirow{4}{*}{ Total } & $\mathrm{M}$ & 0.24 & 0.06 & 0.08 & 0.09 & $<0.001 * *$ \\
\hline & $\mathrm{D}$ & 0.25 & 0.07 & 0.11 & 0.16 & $<0.001 * *$ \\
\hline & $\mathrm{B}$ & 0.15 & 0.02 & 0.07 & 0.01 & $<0.001 * *$ \\
\hline & $\mathrm{L}$ & 0.22 & 0.09 & 0.08 & 0.05 & $<0.001 * *$ \\
\hline
\end{tabular}

*: Significant at $P \leq 0.05$

**: highly Significant at $P \leq 0.01$ 


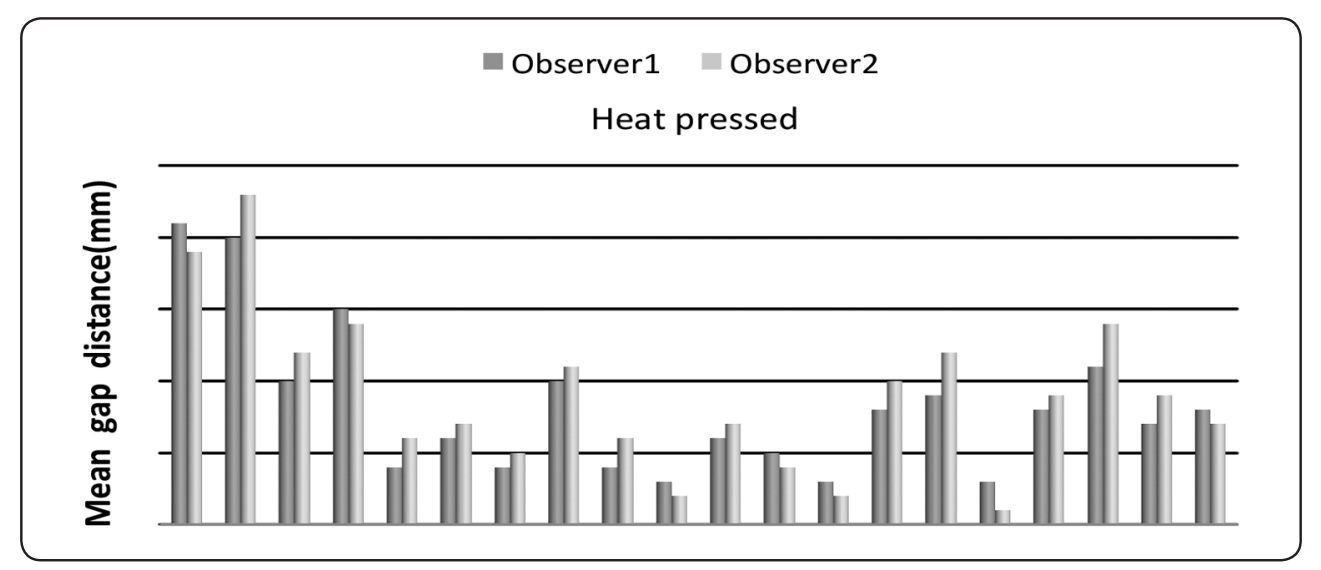

Fig. (5): Bar chart representing mean gap distance values of the two ceramic types measured by the CBCT

Comparison between the two observers of the CBCT

Among the Emax CAD crowns, there was no statistically significant difference between the two observers as regards the mean gap distances measurements at the center point; occluso-axial angle, axial point and shoulder area as well as the overall mean gap at all surfaces. This indicates the reliability of measuring technique despite of the change in observers.

Among the heat pressed Emax crowns, there was no statistically significant difference between the two observers as regards the mean gap distances measurements at the center point, occluso-axial angle, axial point and shoulder area as well as the overall mean gap at all surfaces. This indicates the reliability of measuring technique despite of the change of observers.

\section{Correlation between CBCT and SEM measure- ments}

A positive correlation was found between $\mathrm{CBCT}$ and SEM internal fit measurements for the mesial, lingual and total surfaces.
TABLE (5): Comparison between observer 1 and 2 as regard Emax CAD measurements by CBCT

\begin{tabular}{|c|c|c|c|c|c|c|}
\hline \multirow{2}{*}{$\begin{array}{l}\text { Point of } \\
\text { measurement }\end{array}$} & \multirow{2}{*}{ 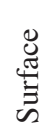 } & \multicolumn{2}{|c|}{ Observer1 } & \multicolumn{2}{|c|}{ Observer2 } & \multirow[b]{2}{*}{$* P$-value } \\
\hline & & Mean & $\mathrm{SD}$ & Mean & $\mathrm{SD}$ & \\
\hline \multirow{5}{*}{ Center } & M & 0.25 & 0.19 & 0.22 & 0.15 & $>0.05$ \\
\hline & $\mathrm{D}$ & 0.26 & 0.12 & 0.28 & 0.10 & $>0.05$ \\
\hline & B & 0.19 & 0.15 & 0.17 & 0.2 & $>0.05$ \\
\hline & $\mathrm{L}$ & 0.22 & 0.14 & 0.20 & 0.12 & $>0.05$ \\
\hline & M & 0.29 & 0.22 & 0.28 & 0.18 & $>0.05$ \\
\hline \multirow{3}{*}{$\begin{array}{c}\text { Occluso- } \\
\text { Axial } \\
\text { Angle }\end{array}$} & $\mathrm{D}$ & 0.28 & 0.18 & 0.26 & 0.14 & $>0.05$ \\
\hline & B & 0.21 & 0.16 & 0.23 & 0.12 & $>0.05$ \\
\hline & $\mathrm{L}$ & 0.26 & 0.13 & 0.28 & 0.14 & $>0.05$ \\
\hline \multirow{5}{*}{ Axial } & M & 0.18 & 0.12 & 0.17 & 0.10 & $>0.05$ \\
\hline & $\mathrm{D}$ & 0.22 & 0.13 & 0.21 & 0.09 & $>0.05$ \\
\hline & B & 0.18 & 0.16 & 0.16 & 0.15 & $>0.05$ \\
\hline & $\mathrm{L}$ & 0.16 & 0.21 & 0.19 & 0.24 & $>0.05$ \\
\hline & M & 0.24 & 0.12 & 0.22 & 0.14 & $>0.05$ \\
\hline \multirow{3}{*}{$\begin{array}{c}\text { Shoulder } \\
\text { Area }\end{array}$} & $\mathrm{D}$ & 0.15 & 0.08 & 0.16 & 0.10 & $>0.05$ \\
\hline & B & 0.11 & 0.06 & 0.12 & 0.07 & $>0.05$ \\
\hline & $\mathrm{L}$ & 0.25 & 0.13 & 0.23 & 0.11 & $>0.05$ \\
\hline \multirow{4}{*}{ Total } & M & 0.24 & 0.06 & 0.23 & 0.20 & $>0.05$ \\
\hline & $\mathrm{D}$ & 0.25 & 0.07 & 0.24 & 0.07 & $>0.05$ \\
\hline & B & 0.15 & 0.02 & 0.17 & 0.01 & $>0.05$ \\
\hline & $\mathrm{L}$ & 0.22 & 0.09 & 0.23 & 0.12 & $>0.05$ \\
\hline
\end{tabular}

*: Non Significant at $P>0.05$ 


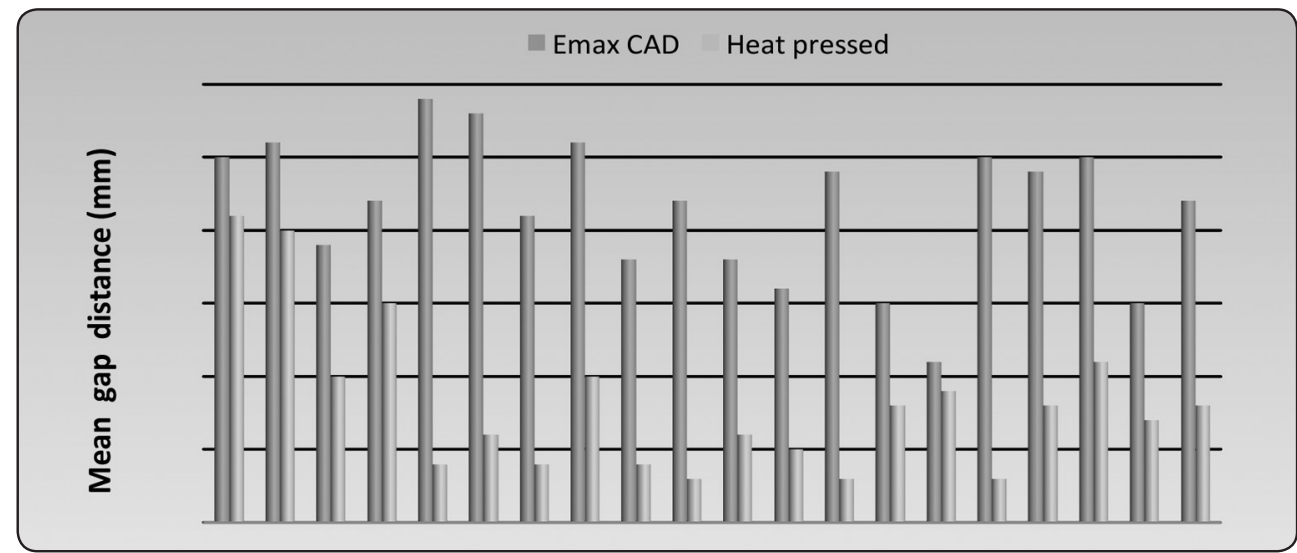

Fig. (6): Bar chart representing mean gap distance values of Emax CAD by the two observers of CBCT

TABLE (6): Comparison between observer 1 and 2 as regard heat pressed Emax measurements by CBCT

\begin{tabular}{|c|c|c|c|c|c|c|}
\hline \multirow{2}{*}{$\begin{array}{c}\text { Point of } \\
\text { measurement }\end{array}$} & \multirow{2}{*}{ Surface } & \multicolumn{2}{|c|}{ Observer1 } & \multicolumn{2}{|c|}{ Observer2 } & \multirow{2}{*}{$* P$-value } \\
\hline & & Mean & $\mathrm{SD}$ & Mean & $\mathrm{SD}$ & \\
\hline \multirow{5}{*}{ Center } & M & 0.21 & 0.13 & 0.19 & 0.10 & $>0.05$ \\
\hline & D & 0.20 & 0.14 & 0.23 & 0.15 & $>0.05$ \\
\hline & B & 0.10 & 0.06 & 0.12 & 0.07 & $>0.05$ \\
\hline & $\mathrm{L}$ & 0.15 & 0.18 & 0.14 & 0.16 & $>0.05$ \\
\hline & M & 0.04 & 0.08 & 0.06 & 0.07 & $>0.05$ \\
\hline \multirow{3}{*}{$\begin{array}{c}\text { Occluso-Axial } \\
\text { Angle }\end{array}$} & $\mathrm{D}$ & 0.06 & 0.12 & 0.07 & 0.10 & $>0.05$ \\
\hline & B & 0.04 & 0.08 & 0.05 & 0.07 & $>0.05$ \\
\hline & $\mathrm{L}$ & 0.10 & 0.20 & 0.11 & 0.21 & $>0.05$ \\
\hline \multirow{4}{*}{ Axial } & M & 0.04 & 0.08 & 0.06 & 0.06 & $>0.05$ \\
\hline & $\mathrm{D}$ & 0.03 & 0.05 & 0.02 & 0.04 & $>0.05$ \\
\hline & B & 0.06 & 0.08 & 0.07 & 0.09 & $>0.05$ \\
\hline & $\mathrm{L}$ & 0.05 & 0.09 & 0.04 & 0.08 & $>0.05$ \\
\hline \multirow{4}{*}{ Shoulder Area } & M & 0.03 & 0.06 & 0.02 & 0.04 & $>0.05$ \\
\hline & $\mathrm{D}$ & 0.08 & 0.15 & 0.10 & 0.12 & $>0.05$ \\
\hline & B & 0.09 & 0.18 & 0.12 & 0.16 & $>0.05$ \\
\hline & $\mathrm{L}$ & 0.03 & 0.06 & 0.01 & 0.03 & $>0.05$ \\
\hline \multirow{4}{*}{ Total } & M & 0.08 & 0.09 & 0.09 & 0.10 & $>0.05$ \\
\hline & $\mathrm{D}$ & 0.11 & 0.16 & 0.14 & 0.16 & $>0.05$ \\
\hline & B & 0.07 & 0.01 & 0.09 & 0.03 & $>0.05$ \\
\hline & $\mathrm{L}$ & 0.08 & 0.05 & 0.07 & 0.04 & $>0.05$ \\
\hline
\end{tabular}

*: Non Significant at $P>0.05$ 


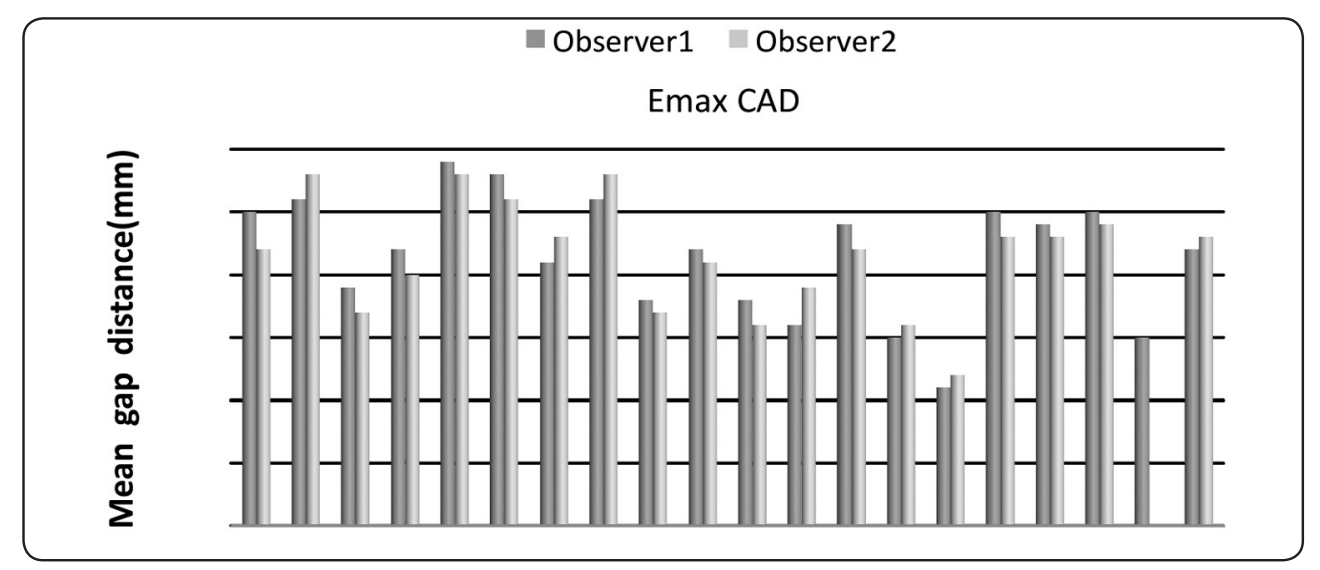

Fig. (7): Bar chart representing mean gap distance values of heat pressed Emax by the two observers of CBCT

TABLE (7): Results of Spearman's correlation for the correlation between internal fit measurements by CBCT and SEM

\begin{tabular}{|c|c|c|}
\hline Surface & $\begin{array}{c}\text { Correlation } \\
\text { coefficient }\end{array}$ & P-value \\
\hline M & 0.707 & $0.022^{*}$ \\
D & 0.546 & 0.09 \\
B & 0.139 & 0.701 \\
L & 0.802 & $0.005^{*}$ \\
Total & 0.570 & $\leq 0.001^{*}$ \\
\hline
\end{tabular}

*: Significant at $P \leq 0.05$

\section{DISCUSSION}

A wide improvement in the microstructure of all ceramic restorations has been made with a rendition of marginal gaps approaching that of metal ceramics. The IPS Emax press and IPS Emax CAD were designed for better mechanical strength and better marginal adaptability with excellent esthetics. A recent clinical study by Gehrt $\mathrm{M}$ et al. ${ }^{(1)}$ verified that IPS Emax press crowns placed in the anterior and posterior regions had a survival rate of $94.8 \%$ over 8 years.

This study assessed the marginal and internal adaptation of heat pressed and chair side processed CAD/CAM lithium disilicate. The technique affected the marginal adaptation favoring the laboratory made heat pressed Emax. A single preparation was made to nullify the preparation effect on the marginal and internal fit. The master preparation was duplicated 20 times with Addition PVS known for its precision and accuracy. Duplication was made with epoxy resin dies known for their accuracy in fine detail reproduction and their resistance to wear during fabrication of the lithium disilicate copings. This was in accordance with Ji et al. ${ }^{(42)}$, Reich et al. ${ }^{(43)}$, Tidehag et al. ${ }^{(14)}$, Cho et al. ${ }^{(44)}$ and Renne et al. ${ }^{(45)}$. Fabrication of the CEREC copings were done following a standardized method by a Professor and a master technician with10 years' experience with the material, in the faculty of Oral and Dental Medicine, Cairo University. The copings were cemented to facilitate cross-sectioning for the SEM examination. This method is known for its accuracy of recording the desired measuring point, repeatability and avoidance of the damage of the crown margin from repeated use of the master die as employed in the direct viewing method, also the horizontal misfit could be assessed which is not possible by the direct viewing ${ }^{(46)}$.

Regarding the SEM measurements, the heat pressed Emax in this study showed a mean vertical gap distance for all the surfaces of $22.8 \mu \mathrm{m} \pm 5.2$ less than Neves FD et al. ${ }^{(23)}$ who reported a mean $36.8 \pm 13.9$, and close to Cho et al. ${ }^{(44)}$ who reported 
a mean value of $27.2 \mu \mathrm{m}$ and $35.1 \mu \mathrm{m}$ on chamfer and shoulder finish line with a conclusion of no statistical difference between the 2 finish line designs in their study. In a study by Mclean JW and von Fraunhofer JA ${ }^{(29)}$ it was shown that marginal gaps of $120 \mu \mathrm{m}$ were clinically accepted and margins less than $50 \mu \mathrm{m}$ were clinically difficult to assess. Therefore the measurements verified in the results of our study were by far less than $120 \mu \mathrm{m}$.

As for the Emax CAD, the mean vertical gap distance for all the surfaces was $47 \mu \mathrm{m}( \pm 16.7)$ which is significantly greater than the heat pressed Emax. This value was close to the results of Hamza TA et al. ${ }^{(7)} 40 \mu \mathrm{m}( \pm 6.7)$ and also close to Neves FD et al. ${ }^{(23)}$ reporting a value of $39.2 \mu \mathrm{m}( \pm 8.7)$. The overall marginal gap was more than Pimenta et al ${ }^{(9)}$ for IPS Zirconia with a measured value of $76.19 \mu \mathrm{m}$. Despite the differences in the measuring methods -the SEM, binoculear microscope and micro CT- with respect to the previously mentioned authors together with the variation in the number of the samples. All these studies were in vitro therefore one can conclude that in vitro studies has the advantage of providing standardized conditions of preparations and experimental procedures resulting in repeatable assessments. The differences between the heat pressing procedure and the $\mathrm{CAD} /$ CAM is that steps in the former are consolidated and the thermal expansion of the investment is matched with the ceramic material, but errors in the preparation design are easier to handle with, in the laboratory procedures according to Renne $\mathrm{W}$ et al. ${ }^{(45)}$. The INEOS CEREC in lab has a laser scanner with a documented accuracy of recording data for the restoration designation. Additionally, the MXCL milling unit has 4 axis for milling -which is a great improvement- but other units like the Everest for example have 5 milling axis producing better internal complexities and better marginal adaptation, according to Neves FD et al. ${ }^{(23)}$ and Hamza TA et al.$^{(7)}$.

The ability of a diagnostic system to accurately evaluate the fit of a fixed restoration is essential in determination of its outcome. There have been many studies in which different methods were used to evaluate the internal and marginal fit of such restorations ${ }^{(20)}$. Evaluation of the marginal adaptation can be performed either qualitatively or quantitatively. Qualitative assessment can be done by direct visualization and by the sense of touch using an explorer. However, this technique is considered to be a difficult diagnostic task, particularly when the restoration margin is interproximal and subgingival ${ }^{(16)}$.

Analyses involving a scanning electron microscope (SEM) has also been repeatedly used for evaluation of the crown-to-die fit. However, it is an invasive technique requiring sectioning, and hence scarification, of the examined tooth, which makes it inapplicable for in-vivo studies ${ }^{(23)}$. Consequently, we chose to measure the internal fit of fixed restorations with both SEM and CBCT. Cone beam computed tomography is a radiographic modality which provides more detailed and precise image information unachievable with conventional radiography while adding a third dimension that immensely assists in radiographic interpretation ${ }^{(41)}$. CBCT imaging systems provide images with submillimeter isotropic voxel resolution achieving a level of spatial resolution that is accurate enough for measurement where precision in all dimensions is important ${ }^{(37)}$.

Studies have demonstrated that clinically acceptable accuracy can be obtained from CBCT measurements for oral applications requiring evaluation of small osseous defects. For periapical lesions evaluation, CBCT views can give accurate measurements in comparison with the real lesions diameter ${ }^{(47)}$. Furthermore, Kamburoglu K et al.$^{(48)}$ in his study, concluded that the cross sectional views of CBCT gave highly accurate measurements when compared to the real physical measurements and the same was confirmed by Naser A and Mehr B ${ }^{(49)}$.

Several studies have proved that the linear measurements derived from CBCT scans were reliable, highly accurate and reproducible compared 
to digital calipers ${ }^{(50,51)}$. The linear measurement accuracy of CBCT was tested in various units and was found comparable to the real measurements ${ }^{(52)}$.

Moreover, no significant difference has been found between the accuracy of CBCT measurements in the axial and coronal sections because the voxels in CBCT are isotropic and this would result in the same image quality in the three orthogonal image planes ${ }^{(38)}$.

As regards the $\mathrm{CBCT}$ measurements carried out in this study, five bucco-lingual sections were examined in each restoration as well as five mesiodistal sections separated by $0.5 \mathrm{~mm}$ intervals. In their study about the influence of preparation design on the fit of ceramic crowns using micro-CT, Kim JH et al. ${ }^{(15)}$ chose similar sections, although with different intervals. Similarly, in another study conducted to compare the marginal and internal adaptation of crowns fabricated with CAD/CAM and heat-press techniques by micro-CT, Mously HA et al. ${ }^{(17)}$ took their measurements on the axial and occlusal surfaces in five mesio-distal and five bucco-lingual sections. In our study, the internal fit of the restoration was measured in each section at the shoulder area, axial wall and occluso-axial line angle bilaterally as well as at the occlusal surface. Similar points were chosen for micro-CT measurements of the crown-to-die fit by Pimenta MA et al. ${ }^{(14)}$ and by Colpani et al. ${ }^{(13)}$ and they considered these points sufficient and reliable to evaluate the adaptation of the crowns.

To the best of our knowledge, no previous studies have been conducted to measure the internal fit of fixed crowns by CBCT. This made our task difficult as regards comparing our results with other researchers work. However, considering the scanning electron microscope as the gold standard, a positive correlation was found between its results and those of the CBCT for the mesial, lingual and total measurements. The statistical analysis of the measurements revealed that both CBCT and scanning electron microscope proved that Emax
CAD had a statistically significantly higher mean gap than Heat pressed Emax at all the points on all the surfaces as well as regards the overall mean gap of all the surfaces except at the center point on the buccal surface where the SEM revealed that Heat pressed Emax showed a statistically significant higher gap than Emax $\mathrm{CAD}$, and at the axial point on the buccal surface where the SEM showed no statistically significant difference between the two ceramic types.

There was no statistically significant difference between the two observers as regard the mean gap distances measurements for all the points as well as for the overall mean gap at all the surfaces both for the Emax CAD and the Heat pressed Emax crowns. This indicates the reliability of the CBCT despite the change of observers. Similar high interobserver reliability of the CBCT measurements was found by Moshfeghi $\mathrm{M}$ et al. (38) and by $\mathrm{Oz} \mathrm{U}$ et al.(53).

\section{CONCLUSIONS}

Within the limitations of the present study, the following conclusions can be made:

1. The fabrication technique significantly affects the fit of lithium disilicate crown-copings favoring the heat pressed Emax.

2. The measurement values of the internal fit for both ceramic types were different, however, they were both within the clinically acceptable range.

3. CBCT has the potential to become a routine noninvasive diagnostic tool for evaluation of the internal fit of fixed crowns. Unfortunately, this application has not been previously explored.

\section{RECOMMENDATIONS}

Further studies should be conducted evaluating CBCT as a measuring tool for assessing the internal fit of fixed crowns on a larger sample size with soft tissue simulation while using different voxel sizes. 


\section{REFERENCES}

1. Gehrt M, Wolfart S, Rafai N, Reich S, Edelhoff D. Clinical results of lithium-disilicate crowns after up to 9 years of service. Clinical oral investigations. 2013;17(1):275-84.

2. Fasbinder DJ, Dennison JB, Heys D, Neiva G. A clinical evaluation of chairside lithium disilicate CAD/CAM crowns: a two-year report. Journal of the American Dental Association (1939). 2010;141 Suppl 2:10s-4s.

3. Lee KB, Park CW, Kim KH, Kwon TY. Marginal and internal fit of all-ceramic crowns fabricated with two different CAD/CAM systems. Dental materials journal. 2008;27(3):422-6.

4. Colpani JT, Borba M, Della Bona A. Evaluation of marginal and internal fit of ceramic crown copings. Dental materials : official publication of the Academy of Dental Materials. 2013;29(2):174-80.

5. Schaefer O, Watts DC, Sigusch BW, Kuepper H, Guentsch A. Marginal and internal fit of pressed lithium disilicate partial crowns in vitro: a three-dimensional analysis of accuracy and reproducibility. Dental materials : official publication of the Academy of Dental Materials. 2012;28(3):320-6.

6. Subasi G, Ozturk N, Inan O, Bozogullari N. Evaluation of marginal fit of two all-ceramic copings with two finish lines. European Journal of Dentistry. 2012;6(2):163-8.

7. Hamza TA, Ezzat HA, El-Hossary MM, Katamish HA, Shokry TE, Rosenstiel SF. Accuracy of ceramic restorations made with two CAD/CAM systems. The Journal of prosthetic dentistry. 2013;109(2):83-7.

8. Liedke GS, Spin-Neto R, Vizzotto MB, Da Silveira PF, Silveira HE, Wenzel A. Diagnostic accuracy of conventional and digital radiography for detecting misfit between the tooth and restoration in metal-restored teeth. The Journal of prosthetic dentistry. 2015;113(1):39-47.

9. Pimenta MA, Frasca LC, Lopes R, Rivaldo E. Evaluation of marginal and internal fit of ceramic and metallic crown copings using x-ray microtomography (micro-CT) technology. The Journal of prosthetic dentistry. 2015;114(2):223-8.

10. Kim JH, Cho BH, Lee JH, Kwon SJ, Yi YA, Shin Y, et al. Influence of preparation design on fit and ceramic thickness of CEREC 3 partial ceramic crowns after cementation. Acta odontologica Scandinavica. 2015;73(2):107-13.

11. Re D, Cerutti F, Augusti G, Cerutti A, Augusti D. Comparison of marginal fit of Lava CAD/CAM crown-copings with two finish lines. The international journal of esthetic dentistry. 2014;9(3):426-35.

12. Euan R, Figueras-Alvarez O, Cabratosa-Termes J, Brufau-de Barbera M, Gomes-Azevedo S. Comparison of the marginal adaptation of zirconium dioxide crowns in preparations with two different finish lines. Journal of prosthodontics : official journal of the American College of Prosthodontists. 2012;21(4):291-5.

13. Chandrashekar S, Savadi RC, Dayalan M, Reddy GTP. A Comparitive Evaluation of the Marginal Adaptation of Zirconium Coping and Nickel-Chromium Coping Using Shoulder Finish Line Design: An Invitro Study. The Journal of the Indian Prosthodontic Society. 2012;12(4):248-51.

14. Tidehag P, Ottosson K, Sjogren G. Accuracy of ceramic restorations made using an in-office optical scanning technique: an in vitro study. Operative dentistry. 2014;39(3):308-16.

15. Bindl A, Mormann WH. Clinical and SEM evaluation of allceramic chair-side CAD/CAM-generated partial crowns. European journal of oral sciences. 2003;111(2):163-9.

16. Fattahi F, Giti R, Torabi K. Marginal Assessment of Crowns by the Aid of Parallel Radiography. Journal of Dental Materials and Techniques. 2015;4(1):29-36.

17. Weyns W, De Boever J. Radiographic assessment of the marginal fit of cast restorations. The Journal of prosthetic dentistry. 1984;51(4):485-9.

18. Federlin M, Sipos C, Hiller KA, Thonemann B, Schmalz G. Partial ceramic crowns. Influence of preparation design and luting material on margin integrity--a scanning electron microscopic study. Clinical oral investigations. 2005;9(1):8-17.

19. Groten M, Axmann D, Probster L, Weber H. Determination of the minimum number of marginal gap measurements required for practical in-vitro testing. The Journal of prosthetic dentistry. 2000;83(1):40-9.

20. Federlin M, Schmidt S, Hiller KA, Thonemann B, Schmalz G. Partial ceramic crowns: influence of preparation design and luting material on internal adaptation. Operative dentistry. 2004;29(5):560-70.

21. Federlin M, Krifka S, Herpich M, Hiller KA, Schmalz G. Partial ceramic crowns: influence of ceramic thickness, preparation design and luting material on fracture resistance and marginal integrity in vitro. Operative dentistry. 2007;32(3):251-60. 
22. Beuer F, Korczynski N, Rezac A, Naumann M, Gernet W, Sorensen JA. Marginal and internal fit of zirconia based fixed dental prostheses fabricated with different concepts. Clinical, Cosmetic and Investigational Dentistry. 2010; 2:5-11.

23. Neves FD, Prado CJ, Prudente MS, Carneiro TA, Zancope K, Davi LR, et al. Micro-computed tomography evaluation of marginal fit of lithium disilicate crowns fabricated by using chairside CAD/CAM systems or the heatpressing technique. The Journal of prosthetic dentistry. 2014;112(5):1134-40.

24. Mously HA, Finkelman M, Zandparsa R, Hirayama H. Marginal and internal adaptation of ceramic crown restorations fabricated with CAD/CAM technology and the heat-press technique. The Journal of prosthetic dentistry. 2014;112(2):249-56.

25. Pelekanos S, Koumanou M, Koutayas SO, Zinelis S, Eliades G. Micro-CT evaluation of the marginal fit of different In-Ceram alumina copings. The European journal of esthetic dentistry : official journal of the European Academy of Esthetic Dentistry. 2009;4(3):278-92.

26. Borba M, Miranda WG, Jr., Cesar PF, Griggs JA, Bona AD. Evaluation of the adaptation of zirconia-based fixed partial dentures using micro-CT technology. Brazilian oral research. 2013;27(5):396-402.

27. Demir N, Ozturk AN, Malkoc MA. Evaluation of the marginal fit of full ceramic crowns by the microcomputed tomography (micro-CT) technique. European Journal of Dentistry. 2014;8(4):437-44.

28. Moldovan O, Luthardt RG, Corcodel N, Rudolph H. Three-dimensional fit of CAD/CAM-made zirconia copings. Dental materials : official publication of the Academy of Dental Materials. 2011;27(12):1273-8.

29. McLean JW, von Fraunhofer JA. The estimation of cement film thickness by an in vivo technique. British dental journal. 1971;131(3):107-11.

30. Boeddinghaus R, Whyte A. Current concepts in maxillofacial imaging. European journal of radiology. 2008;66(3):396-418.

31. Rao GV, Rao SA, Mahalakshmi PM. CONE BEAM COMPUTED TOMOGRAPHY-AN INSIGHT BEYOND EYESIGHT IN CLINICAL DENTISTRY. INNOVATIVE JOURNAL OF MEDICAL AND HEALTH SCIENCE. 2013;2(5).
32. Adibi S. Cone beam computed tomography for general dentists. 2012.

33. De Cock J, Mermuys K, Goubau J, Van Petegem S, Houthoofd B, Casselman JW. Cone-beam computed tomography: a new low dose, high resolution imaging technique of the wrist, presentation of three cases with technique. Skeletal radiology. 2012;41(1):93-6.

34. Silva FCd, Bezerra ISQ, Rebellato NLB, Lima AASd. Cone beam computed tomography and applicability in Dentistry: literature review. RSBO (Online). 2013;10(3):272-7.

35. Macleod I, Heath N. Cone-beam computed tomography (CBCT) in dental practice. Dent Update. 2008; 35(9):590-2.

36. Seth V, Kamath P, Vaidya N. Cone beam computed tomography: third eye in diagnosis and treatment planning. International journal of orthodontics (Milwaukee, Wis). 2012;23(2):17-22.

37. Scarfe WC, Farman AG. What is cone-beam CT and how does it work? Dental clinics of North America. 2008;52(4):707-30, v.

38. Gribel BF, Gribel MN, Frazao DC, McNamara JA, Jr., Manzi FR. Accuracy and reliability of craniometric measurements on lateral cephalometry and 3D measurements on CBCT scans. The Angle orthodontist. 2011;81(1):2635 .

39. Miracle AC, Mukherji SK. Conebeam CT of the head and neck, part 1: physical principles. AJNR American journal of neuroradiology. 2009;30(6):1088-95.

40. Levato CM, Farman AG, Chenin DL, Scarfe W. Conebeam computed tomography: A clinician's perspective. Inside Dentistry. 2009;5(5):66-73.

41. Mehrdad L, Malekafzali B, Shekarchi F, Safi Y, Asgary S. Histological and CBCT evaluation of a pulpotomised primary molar using calcium enriched mixture cement. Eur Arch Paediatr Dent. 2013;14(3):191-4.

42. Ji MK, Park JH, Park SW, Yun KD, Oh GJ, Lim HP. Evaluation of marginal fit of 2 CAD-CAM anatomic contour zirconia crown systems and lithium disilicate glassceramic crown. The Journal of Advanced Prosthodontics. 2015;7(4):271-7.

43. Reich S, Gozdowski S, Trentzsch L, Frankenberger R, Lohbauer U. Marginal fit of heat-pressed vs. CAD/CAM processed all-ceramic onlays using a milling unit prototype. Operative dentistry. 2008;33(6):644-50. 
44. Cho SH, Nagy WW, Goodman JT, Solomon E, Koike M. The effect of multiple firings on the marginal integrity of pressable ceramic single crowns. The Journal of prosthetic dentistry. 2012;107(1):17-23.

45. Renne W, McGill ST, Forshee KV, DeFee MR, Mennito AS. Predicting marginal fit of CAD/CAM crowns based on the presence or absence of common preparation errors. The Journal of prosthetic dentistry. 2012;108(5):310-5.

46. Sorensen JA. A standardized method for determination of crown margin fidelity. The Journal of prosthetic dentistry. 1990;64(1):18-24.

47. Pinsky HM, Dyda S, Pinsky RW, Misch KA, Sarment DP. Accuracy of three-dimensional measurements using cone-beam CT. Dento maxillo facial radiology. 2006;35(6):410-6.

48. Kamburoglu K, Kilic C, Ozen T, Horasan S. Accuracy of chemically created periapical lesion measurements using limited cone beam computed tomography. Dento maxillo facial radiology. 2010;39(2):95-9.

49. Naser AZ, Mehr BB. A comparative study of accuracy of linear measurements using cone beam and multi-slice computed tomographies for evaluation of mandibular canal location in dry mandibles. Dental Research Journal. 2013;10(1):15-9.
50. Damstra J, Fourie Z, Huddleston Slater JJ, Ren Y. Accuracy of linear measurements from cone-beam computed tomography-derived surface models of different voxel sizes. American journal of orthodontics and dentofacial orthopedics : official publication of the American Association of Orthodontists, its constituent societies, and the American Board of Orthodontics. 2010;137(1):16.e1-6; discussion -7 .

51. Lascala CA, Panella J, Marques MM. Analysis of the accuracy of linear measurements obtained by cone beam computed tomography (CBCT-NewTom). Dento maxillo facial radiology. 2004;33(5):291-4.

52. Moshfeghi M, Tavakoli MA, Hosseini ET, Hosseini AT, Hosseini IT. Analysis of linear measurement accuracy obtained by cone beam computed tomography (CBCTNewTom VG). Dental Research Journal. 2012;9(Suppl 1): S57-62.

53. Oz U, Orhan K, Abe N. Comparison of linear and angular measurements using two-dimensional conventional methods and three-dimensional cone beam CT images reconstructed from a volumetric rendering program in vivo. Dento maxillo facial radiology. 2011;40(8):492-500. 